\title{
INVESTIGATION OF HEAT AND MASS TRANSFER IN ACTIVATED CARBON GRANULES/R-134A ADSORBENT PAIR FOR COMPACT ADSORPTION CHILLER
}

\author{
Ahmed N. Shmroukh, Ahmed Hamza H. Ali ${ }^{2}$, Ali K. Abel-Rahman ${ }^{3}$, S. Ookwara ${ }^{4}$ \\ ${ }^{I}$ Energy Resources Engineering Department, Egypt- Japan University of Science and Technology E-JUST, New Borg \\ El-Arab, Alexandria 21934, Egypt \\ ${ }^{2}$ Mechanical Engineering Department, Faculty of Engineering, Assiut University, Assiut, Egypt \\ ${ }^{3}$ Energy Resources Engineering Department, Egypt- Japan University of Science and Technology E-JUST, New Borg \\ El-Arab, Alexandria 21934, Egypt \\ ${ }^{4}$ Chemical Engineering Department, Tokyo Institute of Technology, Tokyo, Japan
}

\begin{abstract}
The present study aims to investigate theoretically with the model validation from the measured data, the operation and design parameters and the effect of the coupled heat and mass transfer mechanisms within a system of adsorber, containing plate and tube heat transfer core, which on its surface the adsorbent immobilized by an adhesive agent. The case study is to estimate the maximum adsorption capacity of activated carbon granules $/ R-134$ a adsorption refrigeration working pair where a measurements shows they has a high adsorption capacity value. The study investigate the effect of operating parameters on the adsorption and desorption process such as temperatures, heating and cooling water mass flow rates as well as the design parameters such as the fin numbers, and adsorbent material data such as mean diameter, pore diameter and specific surface area per unit mass on both adsorber size and performance. Also, at different adsorption temperatures of 25, 30, 35 and $50{ }^{\circ} \mathrm{C}$ using plate and tube adsorber heat transfer core.
\end{abstract}

Keywords: Adsorption Refrigeration, Adsorbent/Adsorbate Pairs, Adsorption Capacity, Theoretical model

\section{INTRODUCTION}

Heat-driven adsorption chillers have existed in patent literature since at least 1909, and adsorption chillers were commercially available since 1920s. In 1929, Dieng et al [1] cited that Miller [2] described several systems that utilized silica gel and sulfur dioxide as an adsorbent/adsorbate pair. Recently the small scale thermal driven development of adsorption refrigeration technology became crucial as it can be driven by solar energy. This is due to that the sorption refrigeration systems are quiet, long lasting, cheap to maintain and environmentally benign [1].

The knowledge of the adsorption bed heat and mass transfer in the adsorption and the desorption processes, is the main issue in optimizing the adsorption bed configuration and the whole adsorption refrigeration system performance. In the open literature, many theoretical researches were addressed to the study and enhancement of the heat and mass transfer inside the adsorption systems, which resultantly affects the system coefficient of performance (COP), specific cooling power (SCP) and other performance parameters. Some studies used computational fluid dynamics (CFD), while, most of the simulation models assumed uniform temperature and pressure or uniform pressure with non-uniform temperature or non-uniform pressure inside the adsorbent bed $[3,4]$.
Ramji et al [5] established a CFD simulation technique to study an activated carbon-methanol adsorption air conditioning system. Their technique simulated the effect of adsorption bed wall thickness on the adsorption temperature and the cooling performance, achieving the suitable design and minimizing the heat loss, this done by applying mass and energy balance on their system and using steady state heat transfer equation to obtain the bed temperature. [5] Concluded that to maintain optimum desorption temperature, the stainless steel bed wall thickness should be 12-20 mm. Bao et al [6] simulated and demonstrated the viability of an adsorption refrigeration -and- electricity cogeneration system by creating a dynamic modeling for the adsorption cycle, this adsorption model was studied independently of the system expander. Their adsorption cycle model contained kinetic model for adsorption rate simulation, and heat transfer model applying the lumped capacitance approach to their adsorption bed components (heat transfer fluid, metallic container wall and adsorbent), to simplify and enhance the general applicability of their numerical modelling. Also, [6] validated their model with their experimental data identifying the proper operation condition for the system. They found that, due to the mutual constraint between the adsorption and the expansion when they link in series, the power output of the cogeneration mode was only around one third of the original expectation under the same condition identified in the individual modelling. Chekirou et al [7] analyzed the evolution of heat 
and mass transfer process in a solar powered adsorption machine, by developing one dimensional mathematical model based on uniform pressure and non-uniform temperature distribution inside the adsorption bed. Their model used to predict the transient behavior of their system and to study the effect of the main parameters on their system performance. The model of [7] was based on the energy equation of heat and mass transfer in the adsorbent bed, the energy balance of the adsorber wall and the adsorption equilibrium equation. They found that the model is a good tool for predicting the temperature and adsorbed mass field, also, they found that enhancing the heat transfer between the solar collector and the adsorber should improve the system performance. Ahmed Hamza H. Ali [8] analyzed the heat and mass transfer in a desiccant enhanced nocturnal radiative cooling-solar collector system, the system was carried out in hot arid areas of Upper Egypt, for air comfort application feasibility study and evaluation. The proposed one dimensional mathematical model was based on, applying the energy balance on the system plates and the section not having desiccant bed, and the mass balance on the desiccant bed section, also, the developed model was based on neglecting energy and moisture accumulation in the air elements and neglecting the stored energy in the system metallic parts. Ahmed Hamza H. Ali [8] found that, using low air mass flow rate was preferable due to obtaining outlet air with low dry bulb temperature less than the ambient temperature. Hassan et al [9] represented the heat and mass transfer inside the adsorption bed of activated carbon-methanol solar adsorption refrigeration system, by introducing a more actual mathematical model based on the variations of ambient temperature and solar radiation during the day, and applying the energy and mass balances on each element of their system. Their model investigated the system performance and the variations in average adsorption bed temperature, adsorbed mass, local thermal conductivity and pressure with respect to time and space. Also, [9] solved the proposed numerical model using the finite difference scheme which was written by a $\mathrm{C}++$ language. They found that, the pressure distribution inside the adsorption bed was nearly uniform varying with time only, and the used adsorption pair thermal conductivity was constant in both space and time. Solmus et al. [10] investigated numerically the coupled heat and mass transfer inside the adsorbent bed of a silica gel/water adsorption cooling unit, using a transient one-dimensional local thermal non-equilibrium model, which based on accounting both internal and external mass transfer resistances. They developed two different energy equations for the single phase adsorbate, and the solid phase adsorbent with the adsorbed adsorbate. They concluded that to improve the performance of the bed, efforts should be focused on reducing intra-particle (interior) mass transfer resistances and heat transfer resistances but not inter-particle (exterior) mass transfer resistances. Yang Pei-zhi [3] established a mathematical model to investigate the heat and mass transfer in adsorbent bed, Yang Pei-zhi [3] discussed the relations between adsorption temperature, coefficient of performance (COP), specific cooling power (SCP) and time during the adsorption process with a cycle time of $24 \mathrm{~min}$. the used model in [3] was assumed that, the mass transfer resistance was not considered, the adsorbent bed pressure was uniform, however, the adsorbent bed temperature gradient was calculated. [3] Concluded that the COP value grows nearly linearly in the whole adsorption process and the SCP value increases sharply in the initial adsorption process and reaches a peak value until the end of adsorption. Maggio et al [4] developed a two-dimensional mathematical model of an adsorption cooling machine consisting of a double consolidated adsorbent bed with internal heat recovery. Their proposed mathematical model was assuming non-uniform temperature and pressure in the consolidated beds. [4] results showed that, the COP increased with respect to the single-bed configuration as well as the cycle time increased on the other hand, the SCP decreased, the variation in the extent of the heat recovery phase affected the COP more than the SCP, also, they indicated that a bed thickness of $2-3 \mathrm{~mm}$ was recommended to obtain high performance. Wang et al [11] predicted the performance of a novel silica gel-water adsorption chiller. They used a lumped parameter model (temperature and pressure are uniform throughout the whole adsorber) with analyzing the heat and mass transfer inside the system, by applying the adsorption equation, energy equations, Liquid refrigerant equilibrium in evaporator and Equilibrium equations in the mass recovery process. They concluded that if the heat source temperature raised to $85^{\circ} \mathrm{C}$, the improvement in the refrigerating capacity would be $76 \%$, if the chilled water inlet temperature was $20^{\circ} \mathrm{C}$, a $12.6 \mathrm{~kW}$ refrigerating capacity and a $0.65 \mathrm{COP}$ were obtained, and for a better refrigerating capacity as well as the COP, a $900 \mathrm{~s}$ heating/cooling time and $180 \mathrm{~s}$ mass recovery time were recommended. Duquesne et al [12] developed a two dimensional transient model for analyzing the coupled heat and mass transfer in a nonlinear thermochemical energy storage system based on adsorption on zeolites, their model consisted of nonlinear coupled partial deferential equations. They found that, their established model is essential for both design and management of such storage system. Leong and Liu [13] established a two-dimensional non-equilibrium numerical model to study the combined heat and mass transfer in a zeolite/water adsorption bed. Their model developed the energy balance on each component of the system and the mass balance for the adsorbent, and then investigated the effect of the configuration parameters on the system performance. Leong and Liu [13] concluded that, the adsorbent thickness and the bed porosity influenced the system performance strongly.

The present study aims to investigate theoretically with the model validation from the measured data, the operation and design parameters and affect the coupled heat and mass transfer mechanisms within a system of adsorber adsorbent immobilized on its surface by an adhesive agent. The case study is to estimate the maximum adsorption capacity of activated carbon granules/R-134a adsorption refrigeration working pairs where a measurements shows they has a higher adsorption capacity value. 
The study investigate the effect of operating parameters on the adsorption and desorption process such as temperatures, heating and cooling water mass flow rates as well as the design parameters such as the fin numbers, and adsorbent material data such as mean diameter, pore diameter and specific surface area per unit mass on both adsorber size and performance. Also, at different adsorption temperatures of 25, 30, 35 and $50{ }^{\circ} \mathrm{C}$ using plate and tube adsorber heat transfer core.

\section{ADSORPTION BED MODEL}

The previously tested facility mainly consists of adsorber, refrigerant tank, water tank, vacuum pump and piping system. The adsorber is a $2 \mathrm{~mm}$ thickness galvanized steel tank with $7 * 5 * 23 \mathrm{~cm}$ in dimension, it is insulated by a 2.5 $\mathrm{cm}$ thickness glass wool and foam insulators, also, it contains the adsorbent heat transfer core which is a rectangular aluminum plate heat exchanger with a cupper pipe, the adsorbent attached to this heat transfer core surface. The refrigerant tank is a $2 \mathrm{~mm}$ thickness galvanized steel tank with $10 * 10 * 20 \mathrm{~cm}$ in dimension, the refrigerant charging valve is welded to its top. The tank is insulated by a $2.5 \mathrm{~cm}$ thickness glass wool insulator. The water tank is a $2 \mathrm{~mm}$ thickness galvanized steel tank with $30 * 30 * 30 \mathrm{~cm}$ in dimension with its cover. It is equipped by a water heater and a thermostat. Cooling and heating water is stored in this tank, to initiate the adsorption and desorption processes. The tank is insulated by a $2.5 \mathrm{~cm}$ thickness glass wool insulator.

\section{MATHEMATICAL MODELLING}

The modelling is the tool for evaluating the performance and sizing of adsorption/desorption systems. The model is built based on the adsorption bed unit shown in Fig.1 for analyzing its heat and mass transfer during adsorption and desorption, the model is obtained by applying the energy and mass balances on the adsorption bed unit and it is established based on the following assumptions:

1- The cooling/heating water mass flow rate is constant without phase change.

2- Thermal contact resistances between tube wall and adhesive, tube wall and fin, fin and adhesive and adhesive and adsorbent are neglected.

3- Radiation between adsorbent, refrigerant and container wall is neglected.

4- One-dimensional temperature gradient in all adsorption unit elements along the flow direction.

5- The adsorbent particles are uniformly distributed in the bed and they are remain inert (no change in surface area or properties) during the adsorption and desorption processes.

6- The properties of the tube, adhesive, fins and bed wall are constant.

7- The refrigerant is the only gas in the adsorption bed according to the vacuum.

8- Energy storage in elements is neglected.

9- The bed wall or the container is perfectly insulated.

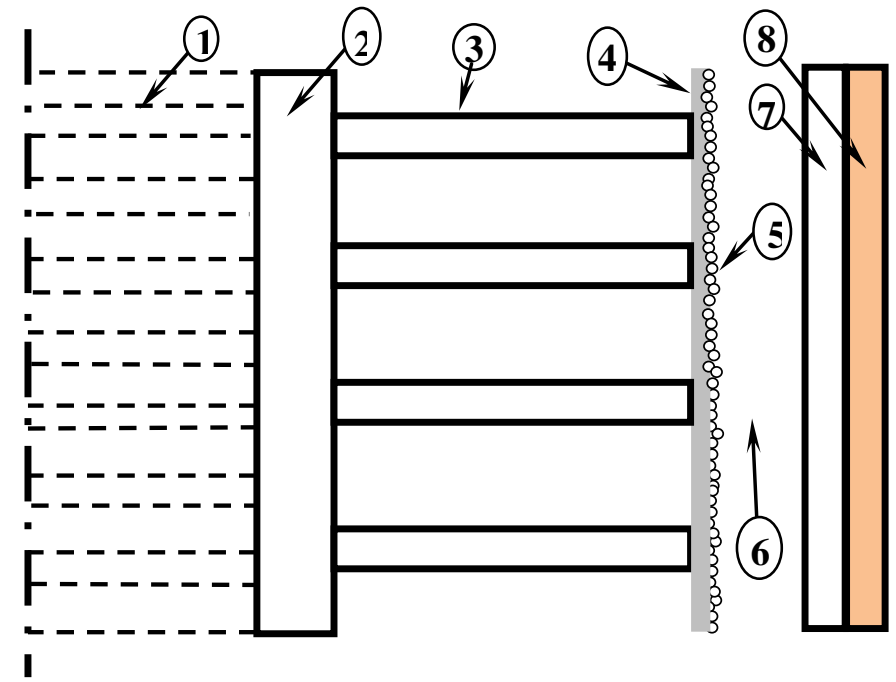

Fig.1 Schematic for the elements arrangement for modeling cooling/heating water, 2) tube, 3) fin, 4) adhesive, 5) adsorbent, 6) refrigerant, 7) container, 8) insulation.

\subsection{Energy Balance}

The energy balance is applied on each element using the thermal resistance circuit shown in Fig 2.
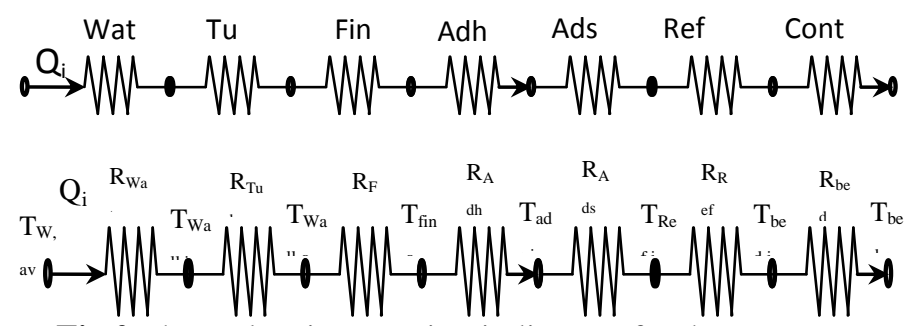

Fig.2 Thermal resistance circuit diagram for the system

For evaluating the input heat rate Qin to the system, the following equation is used,

$$
Q_{i n}=\frac{\Delta T}{\Sigma R}
$$

Where $\mathrm{T}$ is the element temperature in $\mathrm{K}, \mathrm{R}$ is the element thermal resistance in $\mathrm{K} / \mathrm{W}$ and $\mathrm{Q}_{\text {in }}$ is the inlet heat rate to the system in $\mathrm{W}$, and it is also given by

$$
Q_{\text {in }}=\dot{\mathrm{m}}_{\mathrm{w}}\left(H_{\mathrm{w}_{\text {in }}}-H_{\mathrm{w}_{\text {out }}}\right)=\dot{\mathrm{m}}_{\mathrm{w}} \Delta H_{\mathrm{w}}=\dot{\mathrm{m}}_{\mathrm{w}} C p_{\mathrm{w}}\left(T_{\mathrm{win}}-T_{\mathrm{w} \text { out }}\right)
$$

Where $\mathrm{m}_{\mathrm{w}}$ is the heating and cooling water mass flow rate in $\mathrm{kg} / \mathrm{s}, \mathrm{H}_{\mathrm{w}}$ is water enthalpy in $\mathrm{J} / \mathrm{kg}$ and $\mathrm{Cp}_{\mathrm{w}}$ is water specific heat in $\mathrm{J} /(\mathrm{kg} \mathrm{K})$.

\subsection{Mass Balance}

The relations governing the mass transfer for the refrigerant and the adsorbent can be described as follows: 
The change in adsorbed refrigerant mass depends on the adsorption capacity change can be described by the following relation [10 and 14]

$$
\dot{m}_{i m p} A_{a d s}=(1-\xi) V_{a d s} \rho_{a d s} \frac{\partial W}{\partial t}
$$

Where $A_{\text {ads }}$ is the adsorbent area in $\mathrm{m}^{2}, \zeta$ is the adsorbent particle porosity, $\mathrm{V}_{\text {ads }}$ is the adsorbent volume in $\mathrm{m}^{3}, \rho_{\text {ads }}$ is the adsorbent density in $\mathrm{kg} / \mathrm{m}^{3}$, $\mathrm{t}$ is the time in $\mathrm{s}$ and $\mathrm{W}$ is the adsorbent adsorption capacity in $\mathrm{kg}_{\text {Ref }} / \mathrm{kg}_{\text {ads }}$.

The linear driving force kinetic equation used for describing the mass transfer rate between the adsorbent and adsorbate gas can be calculated by the following equation $[10,13,14$, 15,16 and 17]

$$
\frac{\partial W}{\partial t}=K_{A d s}\left(W_{\max }-W\right)
$$

Where $\mathrm{W}_{\max }$ is the maximum adsorption capacity in $\mathrm{kg}_{\mathrm{Ref}} / \mathrm{kg}_{\text {ads }}$ and $\mathrm{K}_{\mathrm{Ads}}$ is the coefficient of adsorption in $1 / \mathrm{s}$, and is given by

The adsorption coefficient can be calculated from the following equation [10 and 16]

$$
K_{\text {Ads }}=15 \frac{D_{e}}{r_{a d s}^{2}}
$$

Where $r_{a d s}$ is the adsorbent particle radius in $m$ and $D_{e}$ is the equivalent diffusion in $\mathrm{m}^{2} / \mathrm{s}$, and is given by the following equation [10,13, 15, 16 and 17]

$$
D_{e}=D_{k} e^{\left(\frac{-E}{R T_{a d s}}\right)}
$$

Where $\mathrm{R}$ is the refrigerant gas constant in $\mathrm{J} /(\mathrm{kg} \mathrm{K}), \mathrm{E}$ is the characteristic energy in $\mathrm{kJ} / \mathrm{kg}$ and $D_{k}$ is the Knudsen diffusion in $\mathrm{m}^{2} / \mathrm{s}$ (the diffusion of adsorbate gas in adsorbent particles obey Knudsen diffusion mechanism), and is given by the following relation [10, 13, 17 and 18]

$$
D_{k}=48.5 d_{\text {pore }}\left(\frac{T}{\mu_{\operatorname{Re} f}}\right)^{0.5}
$$

Where $d_{\text {pore }}$ is the adsorbent particle pore diameter in $\mathrm{m}, \mu_{\text {Ref }}$ is the refrigerant viscosity in $\mathrm{kg} /(\mathrm{m} \mathrm{s})$.

\subsection{System Performance}

For evaluating the performance of a system has the same conditions as the tested adsorption/desorption unit the following relations were used.

For evaluating the refrigeration capacity $Q_{r}$ in $J$, the following equation is used,

$$
Q_{r}=m_{a d s} h_{f g_{\text {Re } f}} W_{\max }
$$

Where $\mathrm{m}_{\mathrm{ads}}$ is the adsorbent mass in $\mathrm{kg}$ and $\mathrm{h}_{\mathrm{fg} \text { Ref }}$ in $\mathrm{J} / \mathrm{kg}$ is the refrigerant enthalpy at a simulated evaporator temperature (for example $10{ }^{\circ} \mathrm{C}$ ).

Thus the refrigeration power $\mathrm{Q}_{\mathrm{r}}$ in $\mathrm{W}$ is given by

$$
\dot{Q}_{r}=\frac{Q_{r}}{t_{c y c}}
$$

$t_{c y c}$ : The cycle time and is given by

$t_{c y c}=t_{\text {Ads }}+t_{\text {Des }}$

Where $t_{\text {Ads }}$ is the adsorption time in $s$ and $t_{\text {Des }}$ is the desorption time in $\mathrm{s}$.

For evaluating the heating power $\mathrm{Q}_{\text {Des }}$ in $\mathrm{W}$ at the desorption stage, the following equation is used,

$$
\dot{Q}_{\text {Des }}=\dot{m}_{w} C p_{w}\left(T_{w_{\text {in }}}-T_{w_{\text {out }}}\right)
$$

For evaluating the coefficient of performance COP, the following equation is used,

$$
C O P=\frac{\dot{Q}_{r}}{\dot{Q}_{\text {Des }}}
$$

For evaluating the specific cooling power SCP in $\mathrm{W} / \mathrm{kg}_{\mathrm{ads}}$, the following equation is used,

$$
S C P=\frac{\dot{Q}_{r}}{m_{a d s}}
$$

\section{RESULTS AND DISCUSSION}

The granular activated carbon adsorbent (Norit SA SUPER) used in the experiments was provided by Norit Nederland B.V. Company. It was produced from coconut shells by steam activation. The quantity of granular activated carbon adsorbent used in the previously done experiments was $139.6 \mathrm{~g}$. The refrigerant which used with this adsorbent was R-134a which is a Hydrofluorocarbon (HFC), its GWP (global warming potential) is 1300 and it has zero ODP (ozone depletion potential) [19].

\subsection{The Condition at $25^{\circ} \mathrm{C}$ of Adsorption with 70, 80 and $85^{\circ} \mathrm{C}$ of Desorption}

Figure 1 shows the relation between the measured and simulated adsorbent temperature inside the adsorber with 
time in $25^{\circ} \mathrm{C}$ adsorption mode. As indicated in the Fig. 1 the simulated adsorbent temperature agrees well with the experimental one with a maximum error of $3.9 \%$. Also, it can be noted that, the adsorbent temperature increased with time due to refrigerant adsorption and decreased when there is no more refrigerant adsorbed.

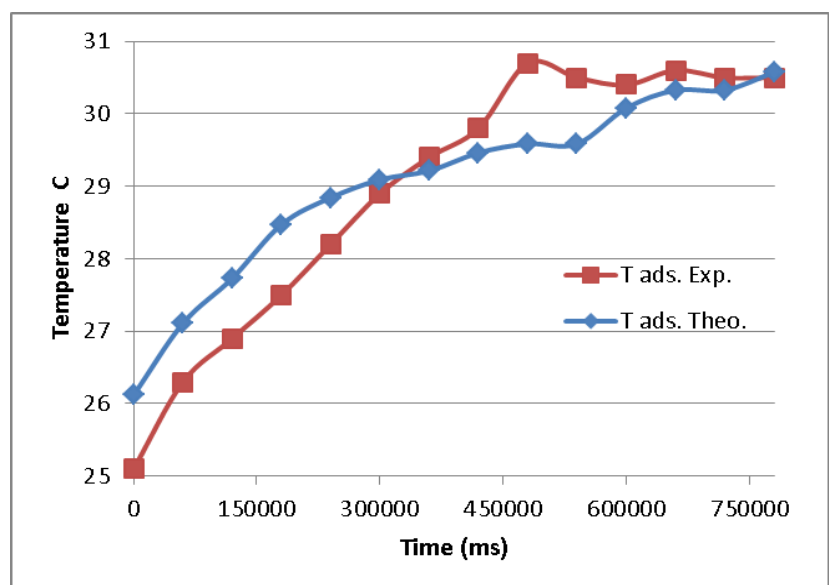

Fig. 1 Comparison between the measured and simulated temperature inside the adsorber with time at $25^{\circ} \mathrm{C}$ adsorption.

Figure 2 indicates the relation between the measured and simulated adsorbent temperature inside the adsorber with time in $70{ }^{\circ} \mathrm{C}$ desorption mode after $25{ }^{\circ} \mathrm{C}$ adsorption. As indicated in the Fig.2 the adsorbent temperature decreased with time due to refrigerant desorption and increased when there is no more refrigerant adsorbed and due to the heat gain from the heating water. Also, the simulated adsorbent temperature agrees with the experimental one with a maximum error of $4.9 \%$.

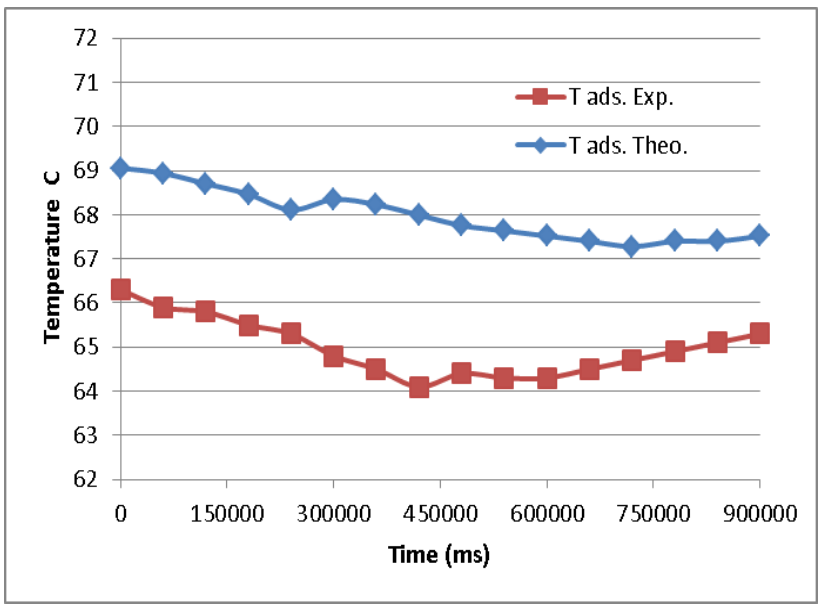

Fig. 2 Comparison between the measured and simulated temperature inside the adsorber with time at $70{ }^{\circ} \mathrm{C}$ desorption after $25^{\circ} \mathrm{C}$ adsorption.

Figure 3 indicates the relation between the measured and simulated adsorbent temperature inside the adsorber with time in $80{ }^{\circ} \mathrm{C}$ desorption mode after $25{ }^{\circ} \mathrm{C}$ adsorption. As indicated in the Fig. 3 there is a good agreement between the simulated adsorbent temperature and the experimental adsorbent temperature with a maximum error of $7.6 \%$. Also, it can be noted that, the adsorbent temperature decreased with time due to refrigerant desorption and increased when there is no more refrigerant adsorbed and due to the heat gain from the heating water.

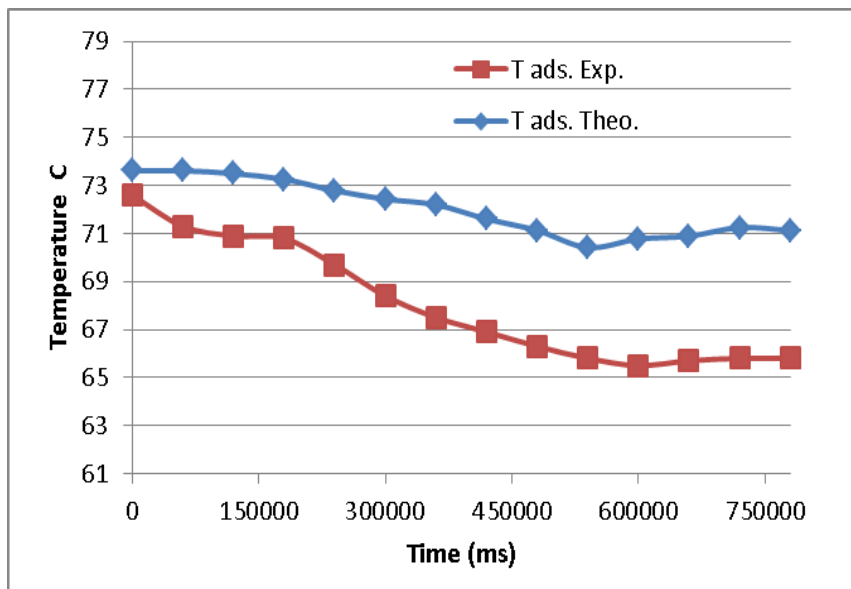

Fig. 3 Comparison between the measured and simulated temperature inside the adsorber with time at $80{ }^{\circ} \mathrm{C}$ desorption after $25^{\circ} \mathrm{C}$ adsorption.

Figure 4 shows the relation between the measured and simulated adsorbent temperature inside the adsorber with time in $85{ }^{\circ} \mathrm{C}$ desorption mode after $25{ }^{\circ} \mathrm{C}$ adsorption. As indicated in the Fig. 4 the adsorbent temperature decreased with time due to refrigerant desorption and increased when there is no more refrigerant adsorbed and due to the heat gain from the heating water. Also, there is a good agreement between the modelled adsorbent temperature and the experimental adsorbent temperature with a maximum error of $9.7 \%$.

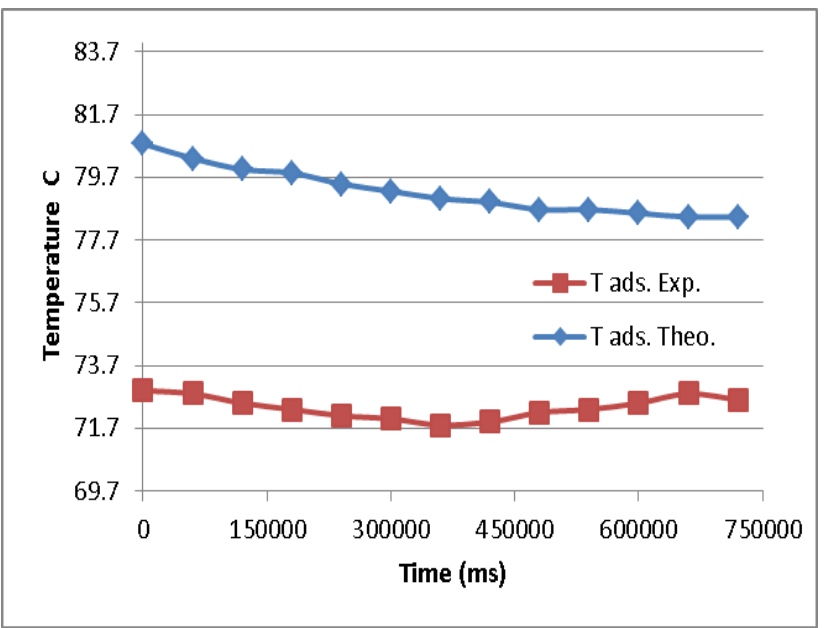

Fig. 4 Comparison between the measured and simulated temperature inside the adsorber, with time at $85^{\circ} \mathrm{C}$ desorption after $25^{\circ} \mathrm{C}$ adsorption.

\subsection{The Condition at $30{ }^{\circ} \mathrm{C}$ of Adsorption}

Figure 5 shows the relation between the measured and simulated adsorbent temperature inside the adsorber with time in $30{ }^{\circ} \mathrm{C}$ adsorption mode. As indicated in the Fig.5 the modelled adsorbent temperature agrees with the 
experimental one with a maximum error of $3 \%$. Also, it can be noted that, the adsorbent temperature increased with time due to refrigerant adsorption and decreased when there is no more refrigerant adsorbed.

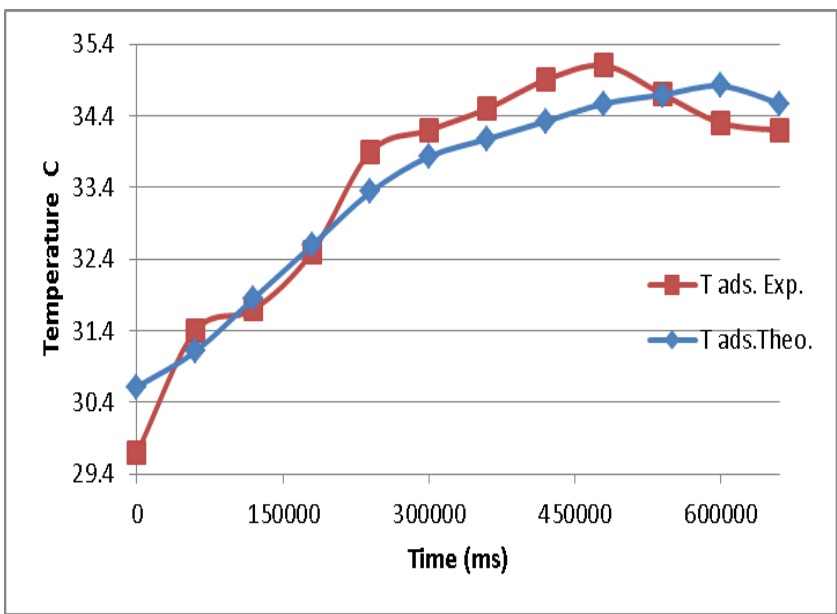

Fig. 5 Comparison between the measured and simulated temperature inside the adsorber with time at $30{ }^{\circ} \mathrm{C}$ adsorption

\subsection{The Condition at $35^{\circ} \mathrm{C}$ of Adsorption}

Figure 6 indicates the relation between the measured and simulated adsorbent temperature inside the adsorber with time in $35^{\circ} \mathrm{C}$ adsorption mode. As indicated in the Fig. 6 the adsorbent temperature increased with time due to refrigerant adsorption and decreased when there is no more refrigerant adsorbed. Also, .there is a good agreement between the modelled adsorbent temperature and the experimental adsorbent temperature with a maximum error of $5 \%$.

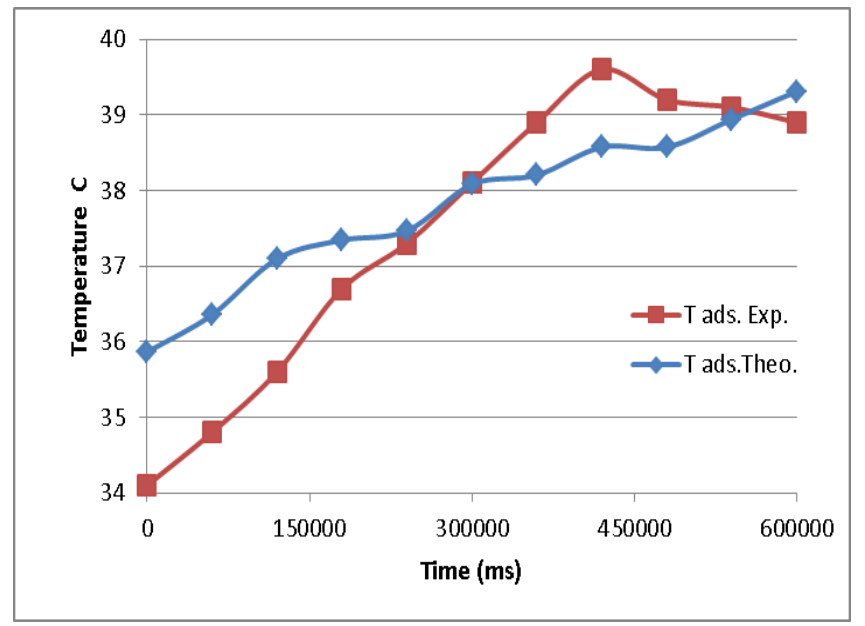

Fig. 6 Comparison between the measured and simulated temperature inside the adsorber with time at $35^{\circ} \mathrm{C}$ adsorption.

\subsection{The Condition at $50{ }^{\circ} \mathrm{C}$ of Adsorption}

Figure 7 indicates the relation between the measured and simulated adsorbent temperature inside the adsorber with time in $50{ }^{\circ} \mathrm{C}$ adsorption mode. As indicated in the Fig. 7 the adsorbent temperature increased with time due to refrigerant adsorption and decreased when there is no more refrigerant adsorbed. Also, .there is a good agreement between the simulated adsorbent temperature and the experimental one with a maximum error of $3 \%$.

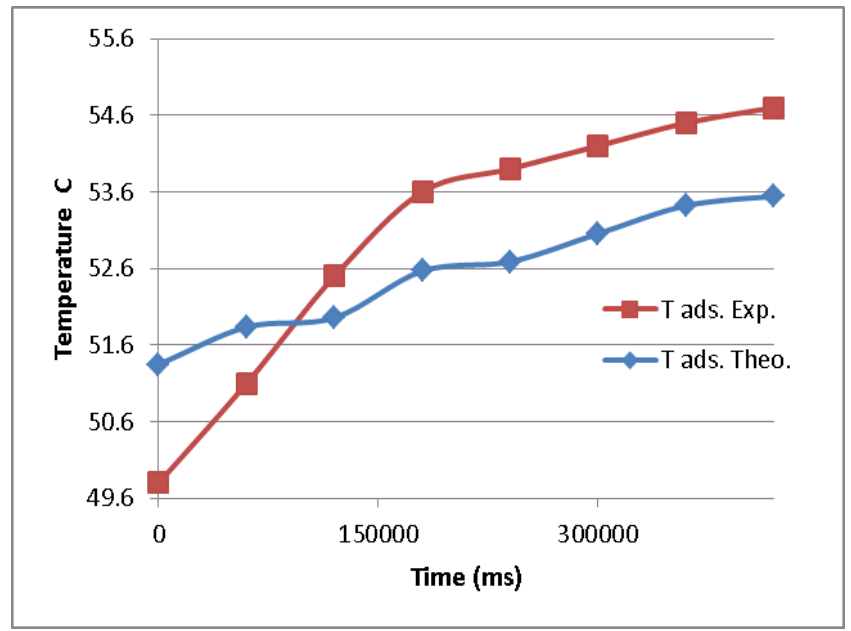

Fig. 7 Comparison between the measured and simulated temperature inside the adsorber with time at $50{ }^{\circ} \mathrm{C}$ adsorption.

\subsection{The Effect of Changing Desorption Temperature}

Figure 8 shows the effect of changing the desorption temperature on COP and SCP. As indicated in the Fig. 8 with increasing desorption temperature a decrease in COP produced due to the increase of the input heating power. On the other hand, SCP is increased because the refrigerating power increased due to increasing the desorbed refrigerant mass. Also, it can be noted that desorption temperature more than $80{ }^{\circ} \mathrm{C}$ should be preferable because of the increase in both COP and SCP because at higher temperature the difference between the inlet and outlet heating water at desorption is decreased.

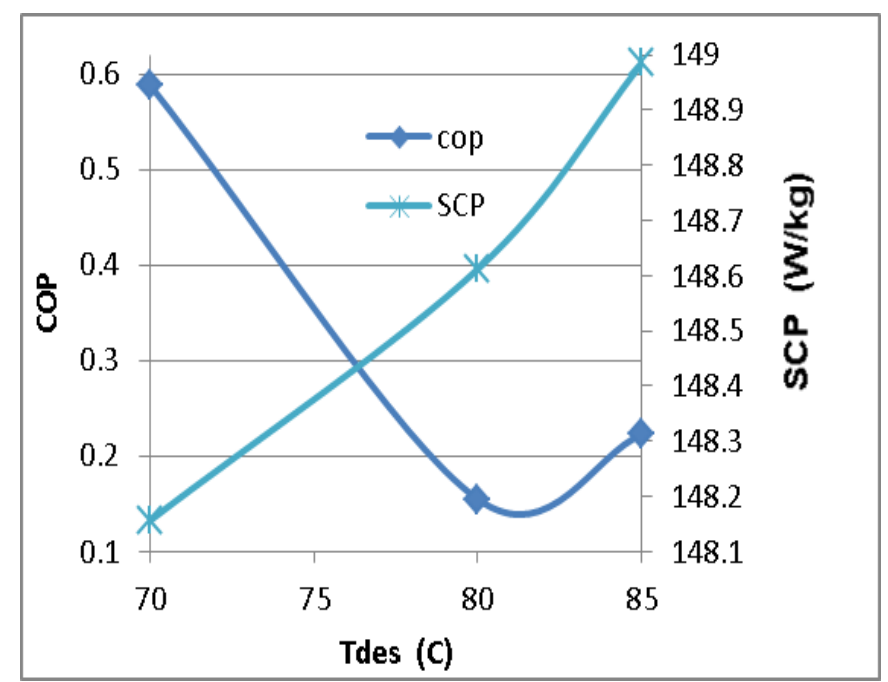

Fig. 8 Variations of COP and SCP with desorption temperature. 


\subsection{The Effect of Changing Fin Number}

Figure 9 shows the effect of changing the fin number on COP and SCP. As indicated in the Fig.9 with increasing the fin number both COP and SCP are increased, due to the increase of available area for the heat and mass transfer rates and increase in refrigeration power. On the other hand, more than 100 fins should be avoided because the space between fins will be very small to accommodate one adsorbent layer at each fin face.

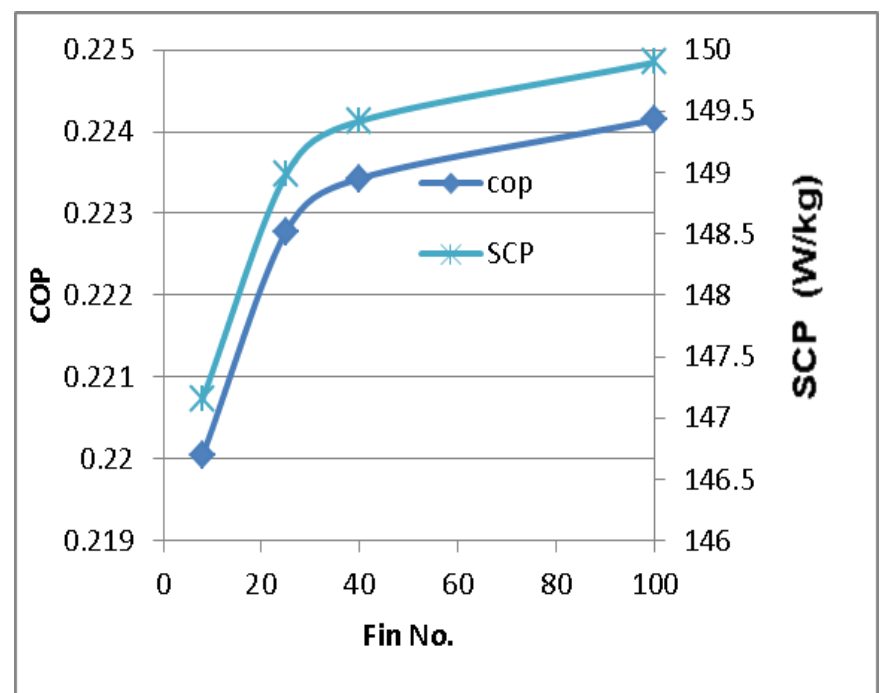

Fig. 9 Variations of COP and SCP with fin number.

\subsection{The Effect of Changing Adsorbent Particle}

\section{Diameter}

Figure 10 indicates the effect of changing the adsorbent particle diameter on COP and SCP. As indicated in the Fig. 10 with increasing the adsorbent particle diameter both COP and SCP are decreased, due to increasing the adsorbent particle resistance for heat and mass transfer. Also, it can be noted that adsorbent particle diameter more than $0.3 \mathrm{~mm}$ should be avoided because of the large decay in COP and SCP.

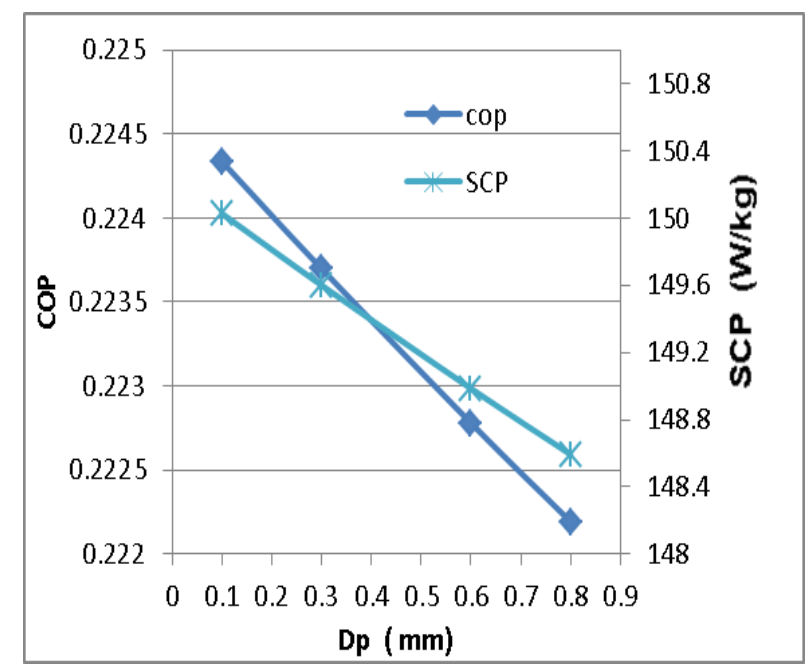

Fig. 10 Variations of COP and SCP with particle diameter.

\subsection{The Effect of Changing Heating Water Mass}

\section{Flow Rate at Desorption}

Figure 11 shows the effect of changing the heating water mass flow rate on COP and SCP. As indicated in the Fig.11 the increase the heating water mass flow rate produce a decrease in COP, due to increasing the input heating power to the system. On the other hand, SCP is a little bit increased the decreased at higher mass flow rates, it can be noted that SCP doesn't affected so much by the heating water flow rate at desorption.

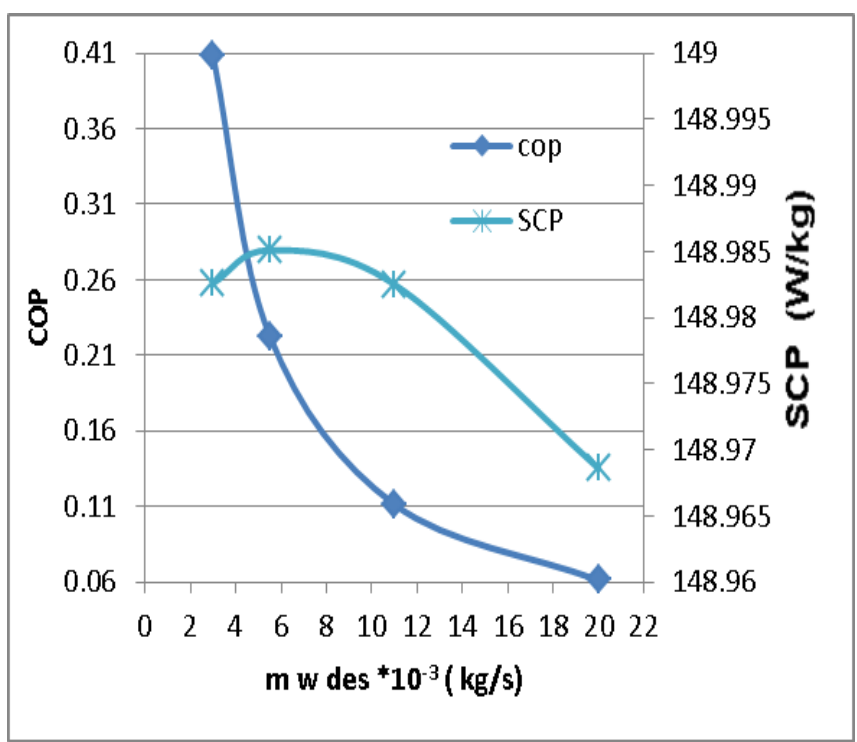

Fig. 11 Variations of COP and SCP with heating water mass flow rate at desorption temperature.

\subsection{The Effect of Changing Adsorbent Pore Diameter}

Figure 12 shows the effect of changing the adsorbent pore diameter on COP and SCP. As indicated in the Fig. 12 with increasing the adsorbent pore diameter both COP and SCP are decreased, due to increasing the attraction forces between the refrigerant molecules and the adsorbent pore wall of smaller size. Also, it should be noted that decreasing the adsorbent pore diameter will produce an increase in the adsorbent specific surface area or the surfaces which ready to attract the refrigerant molecules, which leads to increase in the adsorbed refrigerant mass and the refrigeration power. Pore diameter larger than $3 \mathrm{~nm}$ should be avoided due to the sharp decay in COP and SCP. 


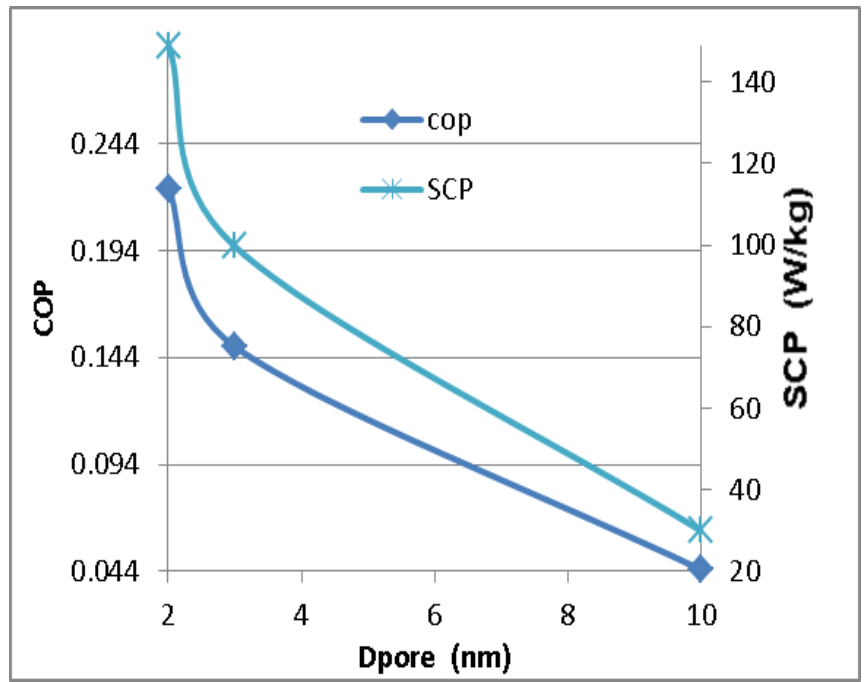

Fig. 12 Variations of COP and SCP with adsorbent pore diameter.

\subsection{The Effect of Changing Adsorbent Specific}

\section{Surface Area}

Figure 13 shows the effect of changing the adsorbent specific surface area on COP and SCP. As indicated in the Fig.13 with increasing the adsorbent specific surface area both COP and SCP are increased, due to increasing the surface which ready for attracting the refrigerant molecules. Also, it should be noted that increasing the adsorbent specific surface area leads to increase in the adsorbed refrigerant mass and the refrigeration power. Specific surface area lower than $1000 \mathrm{~m}^{2} / \mathrm{g}$ should be avoided due to the lower values of COP and SCP.

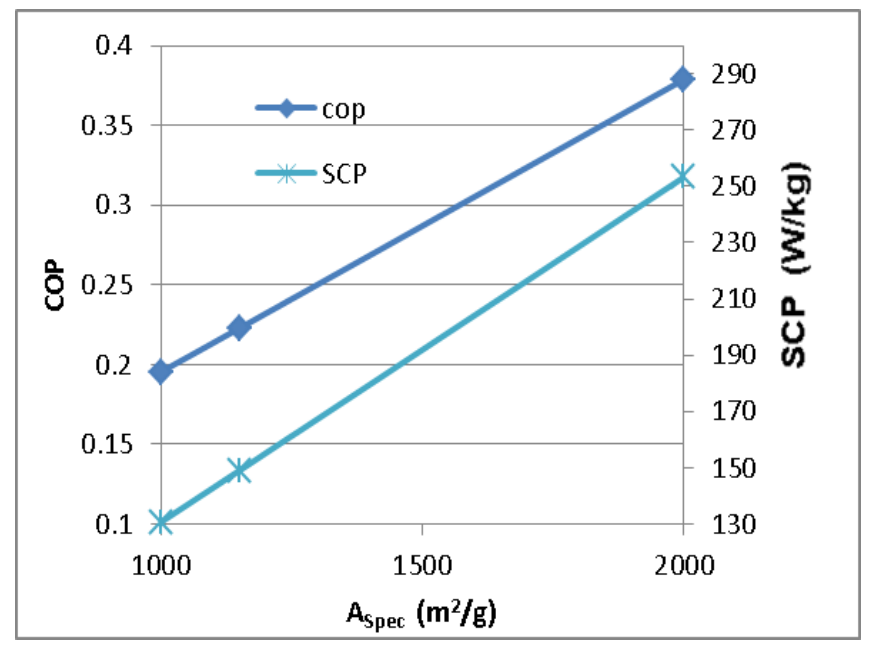

Fig. 13 Variations of COP and SCP with adsorbent specific surface area

\section{CONCLUSION}

A simple generalized analytical model for coupled heat and mass transfer in an adsorption refrigeration bed has been developed. Activated carbon granules/R-134a pair has been considered as the adsorption pair of the simulated adsorption bed of the present study.
The present work showed that

- The maximum adsorption capacity of activated carbon granules/R-134a pair was $0.8025 \mathrm{~kg} / \mathrm{kg}$ at 25 ${ }^{\circ} \mathrm{C}$ and the experimental results showed that maximum adsorption capacity of the same pair was $0.4986 \mathrm{~kg} / \mathrm{kg}$ at $25^{\circ} \mathrm{C}$.

- $\quad$ The temperature inside the adsorption bed showed a good agreement with the results obtained from the previous published experimental results with a reasonable error.

- The coefficient of performance COP, the specific cooling power SCP and the refrigeration power $\mathrm{Q}_{\mathrm{r}}$ obtained by the model was about $0223,148.9 \mathrm{~W} / \mathrm{kg}_{\text {ads }}$ and $20.8 \mathrm{~W}$ respectively, comparing with an input heating power $\mathrm{Q}_{\text {Des }}$ of $93.4 \mathrm{~W}$.

- Increasing the desorption temperature produce a decrease in COP and an increase in SCP, desorption temperature more than $80{ }^{\circ} \mathrm{C}$ should be preferable because of the increase in both SCP and COP.

- Increasing the fin number produce an increase in both COP and SCP. However, increasing the adsorbent particle diameter leads to a decrease in both COP and SCP, particle diameter more than 0.3 $\mathrm{mm}$ should be avoided because of the large decay in COP and SCP.

- Increasing the heating water mass flow rate leads to a decrease in COP due to increasing the input heating power to the system.

- Increasing the adsorbent pore diameter both COP and SCP are decreased, due to increasing the attraction forces between the refrigerant molecules and the adsorbent pore wall of smaller size. Also, decreasing the adsorbent pore diameter will produce an increase the adsorbent specific surface area or the surfaces which ready to attract the refrigerant molecules, which leads to increase the adsorbed refrigerant mass and the refrigeration power. Pore diameter larger than $3 \mathrm{~nm}$ should be avoided due to the sharp decay in COP and SCP.

- Increasing the adsorbent specific surface area both COP and SCP are increased, due to increasing the surface which ready for attracting the refrigerant molecules to provide an increase in the adsorbed refrigerant mass and the refrigeration power. Specific surface area lower than $1000 \mathrm{~m}^{2} / \mathrm{g}$ should be avoided due to the lower values of COP and SCP.

Despite the model simplicity, its analytical nature makes it more useful and easy to use, also, it will have its applicability in the design of adsorption refrigeration beds.

\section{ACKNOWLEDGEMENTS}

The first author would like to acknowledge Prof. Ahmed Hamza and Dr. Shinichi Ookawara for their supervision for the present research. Also, the first author would like to acknowledge Ministry of Higher Education (MoHE) of Egypt for providing a scholarship to conduct this study as well as the Egypt Japan University of Science and Technology (E-JUST) for offering the facility and tools needed to conduct this work. 


\section{REFERENCES}

[1]. Dieng A.O. and Wang R.Z. Literature review on solar adsorption technologies for ice-making and air conditioning purposes and recent developments in solar technology. Renewable and Sustainable Energy Reviews 5 (2001) 313342.

[2]. Habib K., Saha B. B., Chakraborty A., Koyama S.and Srinivasan K. Performance evaluation of combined adsorption refrigeration cycles. International Journal of Refrigeration 34 (2011) 129-137.

[3]. Pei-zhi Yang. Heat and mass transfer in adsorbent bed with consideration of non-equilibrium adsorption. Applied Thermal Engineering 29 (2009) 3198-3203.

[4]. G. Maggio, A. Freni, G. Restuccia. A dynamic model of heat and mass transfer in a double-bed adsorption machine with internal heat recovery. International Journal of Refrigeration 29 (2006) 589-600.

[5]. Harunal Rejan Ramji, Sing Lim Leo, Mohammad Omar Abdullah. Parametric study and simulation of a heat-driven adsorber for air conditioning system employing activated carbon-methanol working pair. Applied Energy 113 (2014) 324-333.

[6]. Huashan Bao, Yaodong Wang, Anthony Paul Roskilly. Modelling of a chemisorption refrigeration and power cogeneration system. Applied Energy 119 (2014) 351-362.

[7]. W. Chekirou, A. Chikouche, N. Boukheit, A. Karaali, S. Phalippou. Dynamic modelling and simulation of the tubular adsorber of a solid adsorption machine powered by solar energy. International Journal of Refrigeration 39 (2014) 137-151.

[8]. Ahmed Hamza H. Ali. Desiccant enhanced nocturnal radiative cooling-solar collector system for air comfort application in hot arid areas. Sustainable Energy Technologies and Assessments 1 (2013) 54-62.

[9]. H.Z. Hassan, A.A. Mohamad, R. Bennacer. Simulation of an adsorption solar cooling system. Energy 36 (2011) 530-537.

[10]. Solmus I. ,Rees D. A. S. ,Yamalı C., Baker D., Kaftanoglu B. Numerical investigation of coupled heat and mass transfer inside the adsorbent bed of an adsorption cooling unit. International Journal of Refrigeration, 35 (2012) 652-662.

[11]. D.C. Wang, Z.Z. Xia, J.Y. Wu, R.Z. Wang, H. Zhai, W.D. Dou. Study of a novel silica gel-water adsorption chiller. Part I. Design and performance prediction. International Journal of Refrigeration 28 (2005) 1073-1083. [12]. Marie Duquesne, Jean Toutain, Alain Sempey, Stéphane Ginestet, Elena Palomo del Barrio. Modeling of a nonlinear thermochemical energy storage by adsorption on zeolites. Applied Thermal Engineering 71 (2014) 469-480.

[13]. K. C. Leong, Y. Liu. Numerical modeling of combined heat and mass transfer in the adsorbent bed of a zeolite/water cooling system. Applied Thermal Engineering, 24 (2004) 2359-2374.

[14]. A. Mihimid. Theoretical study of heat and mass transfer in a zeolite bed during water desorption: validity of local thermal equilibrium assumption. International Journal of Heat and Mass Transfer, 41 (1998) 2967-2977.
[15]. J. Di, J. Y. Wu, Z. Z. Xia, R. Z. Wang. Theoretical and experimental study on characteristics of a novel silica gelwater chiller under the conditions of variable heat source temperature. International Journal of Refrigeration, 30 (2007) 515-526.

[16]. Ismail Solmus, D. Andrew S. Rees, Cemil Yamali, Derek Baker. A two-energy equation model for dynamic heat and mass transfer in an adsorbent bed using silica gel/water pair. International Journal of Heat and Mass Transfer, 55 (2012) 5275-5288.

[17]. Hamid Niazmand, Iman Dabazadeh. Numerical simulation of heat and mass transfer in adsorbent beds with annular fins. International Journal of Refrigeration, 35 (2012) 581-593.

[18]. Douglas M. Ruthven. Principles of adsorption and adsorption processes. 1st edition, John Wiley \& sons, Inc. 1984.

[19]. Dincer I. and Kano glu M. Refrigeration Systems And Applications. A John Wiley and Sons, Ltd., Publication. 2010, Second Edition. 